\title{
La violencia de género y los ingredientes subjetivos distintos del dolo
}

En marzo del año 2015, la Sala de Casación Penal de la Corte Suprema de Justicia se pronunció, por primera vez, sobre el llamado feminicidio. Es preciso advertir que la decisión comentada se ocupó de la modificación introducida al art. $104 \mathrm{CP}$ por el art. 26 de la Ley 1257 de 2008, en concreto, de la circunstancia de agravación número 11, consistente en que el hecho se cometa contra una mujer por el hecho de ser mujer.

Afirmar la tipicidad de los comportamientos que incorporan elementos subjetivos distintos del dolo -como el feminicidio- no es una tarea sencilla y ello obedece, en buena medida, a las dificultades inherentes a su prueba. De ahí la importancia que tanto los teóricos como los prácticos del derecho desarrollen criterios que permitan reducir el margen de arbitrariedad en la aplicación de estas normas y hagan mucho más calculable su aplicación. La decisión comentada, cuya importancia está fuera de toda discusión, alude a la problemática apuntada, aunque no la sortea de la mejor manera: los correctivos introducidos por la Sala no sólo flexibilizan, quizás demasiado, el principio de legalidad, sino que, además, introducen una serie de circunstancias que desnaturalizan el delito mismo de feminicidio.

Daniel Andrés Benavides Ortiz

\section{Gender-based Violence and the Subjective Ingredients Other than Fraud}

In March 2015, the Criminal Cassation Chamber of the Supreme Court of Justice ruled, for the first time on the so-called femicide. It should be noted that the mentioned decision dealt with the amendment to art. CP 104 by art. 26 of Law 1257 of 2008, namely the circumstance of aggravation No. 11 , i.s, that the act is committed against a woman because she is a woman.

Affirming the typical behaviors that incorporate different subjective elements other than fraud, such as the femicide, is not a simple task and this 
is due largely to the difficulties inherent in testing. Hence the importance that both the theoretical and practical lawyers should develop criteria to reduce the margin of arbitrariness in the application of these standards and make their application more calculable. This decision, whose importance is beyond dispute, refers to the targeted problem, but it does not avoid it in the best way: the corrections introduced by the Chamber not only make the principle of legality perhaps too flexible, but also introduce a series of circumstances that denature the crime of femicide same.

\title{
Apartes de la sentencia
}

\author{
CORTE SUPREMA DE JUSTICIA \\ SALA DE CASACIÓN PENAL \\ Magistrado ponente \\ PATRICIA SALAZAR CUÉLLAR
}

Radicación 41457

(Aprobado Acta No. 90)

SP 2190- 2015

Bogotá D.C., marzo cuatro (4) de dos mil quince (2015).

\section{VISTOS:}

Resuelve la Sala el recurso de casación interpuesto por el apoderado de las víctimas contra la sentencia a través de la cual el Juzgado $4^{\circ}$ Penal del Circuito de Medellín y el Tribunal Superior de la misma ciudad condenaron al procesado AOR por el cargo de homicidio agravado.

\section{HECHOS Y ACTUACIÓN PROCESAL:}

1. SPC y AOR, de 35 y 36 años de edad respectivamente, tenían una hija de 6 años.

Hacia septiembre de 2009 él persiguió a la primera desde su casa en la parte alta del Barrio Trece de Noviembre en Medellín hasta una tienda cercana, donde le propinó nueve puñaladas. Fue "un ataque de celos" dijeron algunos familiares de ella. Pasados unos días, cuando aún la mujer se recuperaba de las lesiones, el hombre regresó a la vivienda familiar. Y se quedó allí. Amenazaba con llevarse a la hija si su compañera lo expulsaba del lugar.

En septiembre de 2012 el hombre la golpeó al encontrarla chateando cuando volvió de su trabajo. A raíz de eso, contó FAV, su hermana, "le sacó la ropa" a la calle y él se fue a vivir en otro lugar, en una habitación que rentó en una casa cercana. Le dijo a SPC "que por sobre el cadáver de él ella se conseguía a otra persona". 
Los días que siguieron fueron de acoso total. El hombre llamada "a todas las horas a los celulares y al fijo para comprobar que ella estaba sola", señaló la misma fuente. Los viernes se embriagaba, iba a la casa de ella "y le gritaba perra sucia te voy a matar".

Y cumplió. El 17 de noviembre de 2012 consiguió que lo acompañara voluntariamente al motel Romantic Suites, ubicado en la calle 53 No. 47-27, en el centro de la ciudad de Medellín. Ingresaron al lugar hacia las 3 de la tarde, dialogaban "cómodamente" - dirían luego las autoridades de policía en su informe- y subieron a la habitación 402. De allí AOR salió una hora después, luego de asestarle a la mujer una puñalada en la parte izquierda del tórax, a causa de la cual falleció en el lugar.

2. El 21 de noviembre de 2012, tras su entrega voluntaria a las autoridades, ante un Juzgado de Garantías la Fiscalía le imputó a AOR el cargo de homicidio agravado (Arts. 103 y 104-1/11 del C. P.) y éste admitió su responsabilidad penal. Acto seguido fue detenido preventivamente.

3. El Juzgado $4^{\circ}$ Penal del Circuito de Medellín, luego del trámite de rigor, lo condenó el 18 de febrero de 2013 a 280 meses de prisión y a la sanción accesoria de inhabilitación para el ejercicio de derechos y funciones públicas por un tiempo igual al de la pena principal. No le concedió la condena de ejecución condicional ni la prisión domiciliaria.

4. El defensor apeló ese pronunciamiento y el Tribunal Superior de Medellín, a través del fallo recurrido en casación, expedido el 15 de marzo de 2013, le impartió confirmación con las siguientes modificaciones: excluyó la agravante 11 del artículo 104 del Código Penal ("cometer el homicidio contra una mujer por el hecho de ser mujer") y fijó en 200 meses las penas de prisión y de inhabilitación de derechos y funciones públicas.

\section{LA DEMANDA:}

\section{Cargo único. Violación directa de la ley sustancial por falta de aplicación del artículo 104-11 del Código Penal.}

Señaló el recurrente que al dejarse de aplicar esa disposición resultaron igualmente vulnerados los artículos 13, 42, 43, 93 y 94 de la Constitución Política, la Convención para la eliminación de todas las formas de discriminación contra las mujeres, la Convención americana para prevenir, sancionar y erradicar la violencia contra las mujeres, la Ley 1257 de 2008 y las cláusulas de igualdad y no discriminación contempladas en la Declaración universal de los derechos humanos, en la Declaración americana de los derechos y deberes del hombre, en el Pacto internacional de derechos civiles y políticos y en la Convención americana sobre derechos humanos. 
Se equivocó el Tribunal -dijo el profesional- al concluir que se trató simplemente de un crimen pasional originado en los celos y que en ningún momento el procesado le causó la muerte a su pareja por el hecho de ser mujer. Esta agravante específica del homicidio la dedujo la Fiscalía en la formulación de imputación y AOR se allanó a ella.

Se han señalado, "en contextos de pareja", como patrones del feminicidio "la existencia de una historia de violencias", el ejercicio por parte de los agresores de "acciones de instrumentalización y cosificación de las vidas y cuerpos de la mujer", la presencia de "relaciones de dominio o poder de los agresores sobre la mujer" e impunidad.

Esas particularidades concurren en el presente caso. El procesado, en efecto, intentó matar a su compañera permanente propinándole nueve puñaladas (la Fiscalía calificó erróneamente esa conducta como lesiones personales), la "cosificaba" al considerarla "solo suya", era evidente el dominio que ejercía sobre ella a través de la violencia y era manifiesta, igualmente, "la impunidad continuada" respecto de las agresiones.

Estado patriarcal y machismo, a juicio del censor, desarrollan "la discriminación, la violencia contra las mujeres, toda la violencia feminicida y el feminicidio propiamente dicho". El crimen pasional, la celotipia y las emociones no controladas, "se constituyen en un dispositivo malsano de género, que minimiza la violencia contra las mujeres". Según la autora Myriam Jimeno el crimen pasional es una construcción cultural. En la "configuración emotiva están imbricadas las creencias, los sentimientos y su verbalización, con la estructura de las jerarquías sociales". A pesar de ello "ciertos dispositivos discursivos presentan tal crimen como si obedeciera a una propensión o inclinación natural ocultando sus resortes culturales". El "uso de la emoción como atenuante", por tanto, "parece cumplir funciones ideológicas en el ejercicio de las jerarquías sociales y de género, como lo señalara Lutz para la que llama la cultura angloamericana".

El llamado crimen pasional, en fin, "oculta las razones de misoginia y dominación masculina, existentes detrás de los asesinatos contra las mujeres".

En otros textos citados por el casacionista se afirma que en las sociedades patriarcales son frecuentes los asesinatos de mujeres a manos de hombres, que en su mayoría son feminicidios y se causan por cosificación, posesión, celos, odio, placer, erotismo. La violencia es clave para someter a las mujeres y sostener su dominación. La intimidación a ellas -según Robert Connel-

"se produce desde el silbido de admiración en la calle, al acoso en la oficina, a la violación y al ataque doméstico, llegando hasta el asesinato por el dueño patriarcal de la mujer, como en algunos casos de maridos separados. Los ataques físicos se acompañan normalmente de abuso verbal. La mayoría de los hombres no ataca o acosa a las mujeres; pero los que lo hacen, difícilmente piensan que ellos son desquiciados. Muy por el contrario, en general sienten que están completamente justificados, que están ejerciendo un derecho. Se sienten autorizados por una ideología de supremacía".

170 Cuadernos de Derecho Penal, ISSN: 2027-1743 / 2500-526x [En línea], julio-diciembre de 2015 
A juicio del casacionista, en la definición del sentido y alcance que se debe dar a la agravante 11 del artículo 104 del Código Penal, los estudios de género contribuyen a proporcionar la respuesta correcta. Y si se estimara que existe la necesidad de probar la misoginia del sujeto activo, se recuerda que en el presente caso el procesado se allanó a los cargos y, además, que los crímenes pasionales son verdaderos feminicidios, como ya se advirtió.

De alguna manera la sentencia recurrida, de otro lado, "parece dejar la idea de que si se mata a una mujer, o a cualquiera, y el sujeto activo se entrega no es tan grave". No es así para el recurrente en el presente caso. Se trató de un crimen atroz contra una mujer a la cual el homicida había apuñaleado pocos años antes. Y éste "desarrolló la misma estrategia" que la vez anterior al presentarse voluntariamente a las autoridades, "con la diferencia que antes fue rápidamente liberado y en esta ocasión no; en la primera oportunidad el cuaderno fue abierto por la Fiscalía por lesiones personales, cuando en realidad se trataba de una tentativa de homicidio, que ha llevado a la familia a considerar la demanda de orden administrativo contra el Estado colombiano por la falta de acción de las autoridades judiciales. En aquella ocasión las cuchilladas no fueron más porque al señor AOR le interrumpieron su accionar criminal otras personas".

Reiteró a continuación frente al tema de la demanda que para imputar la agravante 11 del artículo 104 del Código Penal, "no es necesario que el agente asesino afirme o reconozca que cometió el hecho porque se trataba de una mujer. $Y$ mucho menos en los casos en que confiesa el hecho y se allana a cargos. No se trata de un asunto que sea consciente en el homicida, ni siquiera, por lo general, en los hombres y mujeres, y hasta intersexuales, que componen una sociedad. Ello no lo justifica, ni lo exonera de responsabilidad, ni como sujeto desde el punto de vista de la psicología, ni como acreedor de un reproche penal. La razón está dada en la cultura. En el estado patriarcal que vive nuestro país, en el machismo a través del cual se manifiesta".

No sin señalar el censor, por último, que el caso es una buena oportunidad para desarrollar la jurisprudencia, le pidió a la Sala casar la sentencia impugnada y confirmar la proferida por la primera instancia, "excepto en lo que hace a la cuantificación de la pena accesoria".

\section{ACTUACIÓN ANTE LA CORTE:}

En la audiencia de sustentación oral intervinieron el apoderado de las víctimas, el Fiscal Delegado ante la Corte, la Procuradora Delegada ante la Corte y el defensor del procesado.

\section{El apoderado de las víctimas.}

Reiteró en lo fundamental los argumentos de la demanda, trajo a colación pasajes de otros autores en relación con la violencia de género, recordó que de acuerdo con la Corte Interamericana de Derechos Humanos en la definición de discriminación contra la mujer se incluye la violencia basada 
en el sexo -es decir la dirigida contra ella por su condición de mujer-, e hizo hincapié en la idea del feminicidio como "un hecho que se relaciona con la intención siempre de doblegar, controlar y someter la sexualidad y las decisiones de las mujeres sobre su vida, efectos, relaciones, cuerpo y ser mismo".

Le solicitó a la Sala, finalmente, reconocer que en el presente caso el procesado cometió un feminicidio, incorporando en el pronunciamiento la perspectiva de género.

\section{El Fiscal.}

Para este funcionario no hay lugar a casar el fallo impugnado. El motivo del homicidio fue la celotipia del procesado y no la condición de mujer de la víctima. Y aunque se admitiera la ocurrencia del feminicidio como lo alega el censor, no se podría agravar la pena impuesta porque el defensor fue apelante único de la sentencia de primera instancia.

La circunstancia de agravación 11 del artículo 104 del Código Penal, adicionalmente, no fue debidamente motivada en la imputación ni en el fallo de primer grado. El a quo, además, no podía mantener atribuida doblemente una agravante respecto de un mismo supuesto de hecho, de conformidad a como lo tiene definido la Corte "en temas de delitos sexuales al precisar que la circunstancia de agravación punitiva prevista en el numeral $2^{\circ}$ del artículo 211 del Código Penal no se aplica cuando concurre con la del numeral $5^{\circ}$ ibídem ante una modificación sobreviniente prevista en la Ley 1236 de 2008, que en criterio de la Fiscalía guarda estrecha similitud con este caso por la modificación que hiciera la Ley 1257 del mismo año, en cuanto a los agravantes del homicidio que recae sobre una mujer, esposa o compañera permanente y/o por el hecho de ser mujer (sentencia del 17 de agosto de 2011, radicado 33006)".

La discusión, entonces, a juicio del Fiscal, es si la rebaja punitiva debe ser del 30\% establecido por la primera instancia o del 50\% decretado por el ad quem. Y si bien es cierto que dicho aspecto no fue objeto de casación, no sería posible la reforma de la pena en perjuicio del procesado porque el defensor fue único apelante. De todas formas, con independencia de lo anterior, para la Fiscalía son acertados los argumentos que condujeron al Tribunal a realizar el máximo descuento de pena permitido por el artículo 351 de la Ley 906 de 2004.

Tras destacar la importancia de que la Corte defina si el presente caso corresponde a un feminicidio, finalizó la Fiscalía su alegato señalando que a su juicio no se estructura aquí una hipótesis de esa naturaleza. Esa conclusión se sustenta en la definición que de ese fenómeno hizo la Corte Interamericana de Derechos Humanos en la sentencia expedida el 16 de noviembre de 2009 (caso González y otras Campo Algodonero contra México). El concepto de feminicidio, según ese Tribunal, hace referencia a homicidios motivados en el odio o el desprecio al género femenino y no a crímenes pasionales aislados 
como el que aquí se juzga. En consecuencia, la interpretación del Tribunal Superior de Medellín no contraría los instrumentos internacionales sobre protección a la mujer como lo sugiere el demandante.

\section{La Procuradora.}

Para la Delegada, a diferencia del interviniente anterior, los casos de homicidios por celos contra mujeres son emblemáticos de feminicidio en la doctrina internacional y en los tratados de derechos humanos de las mujeres.

El maltrato físico o verbal que ejerce el hombre en una relación de pareja, el menosprecio por su esposa o compañera, el control sobre ella a través de sentirla su propiedad, representa "un contexto de inequidad de género en virtud del cual la escalada de la violencia tiene su máxima expresión en la supresión de la vida de la mujer que no es más que un feminicidio", cuya estructuración no requiere "las manifestaciones expresas de odio contra todas las mujeres" por parte del autor de la conducta.

Cuando un hombre mantiene o mantuvo "una relación de pareja o de nexo familiar con una mujer en un contexto de celos, vigila sus movimientos, controla entradas y salidas de la mujer, con quién habla ésta, cómo se viste, dónde vive, está cosificándola pues su relación con esa mujer es en términos de propiedad". Los celos, a su turno, "no son más que la manifestación de propiedad que se ejerce o pretende ejercer sobre la persona así cosificada y como propietario el sumo acto de dominio es el que implica la plena disposición del objeto poseído que no es otro que su destrucción, para el caso de una mujer su muerte". Así las cosas, expresiones del tipo "si no eres mía no eres de nadie", "si te veo con otro te mato" o "sobre mi cadáver consigues a otro" son propias de la cosificación de la mujer.

En el caso examinado, prosiguió la Agente del Ministerio Público tras relacionar los casos que corresponden a feminicidio según algunas legislaciones latinoamericanas, la muerte de Sandra Patricia Correa se presentó "en el contexto de un episodio de celos por parte de quien ya había" atentado contra su vida. Eso significa que existía un antecedente de violencia contra la víctima, a quien el procesado, además, tenía sometida a estrecha vigilancia y amenazaba de muerte y con quitarle a la hija común "si salía con otras personas". La relación con ella era "de dominio, propiedad y manipulación", ocurriendo el atentado contra su vida, entonces, "en cumplimiento de algunos de los presupuestos que a nivel de legislación comparada permiten calificar el homicidio de una mujer como un feminicidio".

Para la Delegada, pues, el Tribunal incurrió en el error denunciado por el casacionista. Le solicitó a la Corte, en consecuencia, casar parcialmente la sentencia impugnada para reconocer que lo sucedido fue un feminicidio y disponer que el descuento punitivo por el allanamiento a los cargos del procesado sea el $30 \%$ decretado por el a quo. Esto último "ante la necesidad de que la condena del procesado refleje efectivamente la justa retribución que un feminicidio 
manda, por las víctimas como además por los compromisos internacionales de efectiva represión de los responsables de la violencia contra la mujer".

Adicionalmente -finalizó la Procuradora-, como bien argumentó en torno a la rebaja de pena el a quo, cuando se entregó el indiciado ya la Fiscalía contaba "con elementos de conocimiento que señalaban sin duda alguna la identidad del autor, la forma de comisión del punible, el móvil del mismo, la historia de violencia precedente a este homicidio de donde el 30\% de descuento se muestra aquí como razonable y el 50\% como un descuento desmesurado frente al ahorro que para la administración de justicia efectivamente implicó el allanamiento a cargos y es que no puede seguirse manteniendo por la judicatura la idea de que los hombres que matan a sus mujeres lo hacen porque las aman mucho y lo que hay que hacerles es un monumento si ellos se entregan, casi que pedirles perdón por haberlos llevado a juicio".

\section{El defensor.}

Pidió no casar la sentencia impugnada en casación porque a su juicio la segunda instancia acertó al excluir la agravante punitiva 11 del artículo 104 del Código Penal.

Precisó que por el hecho de que en una oportunidad anterior su representado hubiera agredido por celos a la víctima, no se puede asegurar que ejerciera "una violencia sistemática y constante sobre ella" como para sostener en el presente caso que la mató por el hecho de ser mujer.

Para el abogado no se formuló correctamente en la demanda un cargo contra el ad quem por otorgarle al acusado, en razón del allanamiento a cargos, una mayor rebaja punitiva a la decretada por la primera instancia. En su criterio, de todas formas, no constituye una incorrección el otorgamiento a su defendido de un descuento en la pena que consagra la ley. Se trata simple y llanamente de una particularidad del sistema acusatorio de la Ley 906 de 2004.

\section{CONSIDERACIONES DE LA CORTE:}

1. El Tribunal Superior de Medellín, apoyado en la obligación judicial de proteger los derechos fundamentales del procesado que admite los cargos formulados por la Fiscalía, estimó que resultaba lesivo del principio de legalidad atribuirle en el presente caso al inculpado AOR la circunstancia de agravación del homicidio prevista en el numeral 11 del artículo 104 del Código Penal, es decir, la de causar la muerte "contra una mujer por el hecho de ser mujer".

Para la Corporación judicial, de acuerdo con la entrevista suministrada por FAV y la denuncia de BSR (referida a un hecho anterior), "se establece" que AOR "dio muerte a su pareja por cuestiones pasionales relacionadas con los celos que sentía por el comportamiento de la mujer". Agregó la segunda instancia: 
"De manera que si la muerte se debió a cuestiones pasionales, no se entiende por qué la Fiscalía le imputó al procesado la agravante del numeral 11, sin que ninguna explicación de su deducción se encuentre en el escrito de acusación, que no fuera la simple indicación de la agravante (fl. 3 de la carpeta), lo cual no mereció tampoco ningún comentario del juez de conocimiento en su sentencia cuando era su deber verificar su real existencia.

"El feminicidio -siguió el ad quem-, neologismo empleado para designar el asesinato evitable de mujeres por razones de género (como así lo definió la Corte Interamericana de DD.HH en una sentencia que condenó al Estado de México por la muerte de varias mujeres en ciudad Juárez en el año 2001), es un delito motivado por la misoginia, que implica el desprecio y odio hacia las mujeres, lo cual ciertamente no aplica en este caso, donde aquello que originó el actuar del procesado fue la celotipia de un compañero sentimental, que lo llevó al absurdo de acabar con la vida de su compañera, contra quien por la misma razón había atentado en ocasión pasada"

"Atendiendo al principio de estricta tipicidad que le fue vulnerado al procesado -finaliza la cita-, la Sala oficiosamente excluirá dicha agravante, así esta determinación no tenga ninguna incidencia en la dosificación de la sanción, como quiera que el Juez impuso la pena mínima establecida para el delito de homicidio agravado, subsistiendo de todas maneras la primera agravante punitiva, como que se estableció que el procesado era el compañero sentimental de la hoy occisa, con quien había procreado una hija".

La exclusión de la agravante, en realidad, la solicitó el defensor en la apelación. El apoderado de las víctimas pidió su restablecimiento en la demanda de casación. Y la Corte, consciente desde la admisión de ésta que su éxito es intrascendente al no representar para la parte proponente ningún beneficio concreto, decidió admitirla con la clara finalidad de desarrollar la jurisprudencia.

2. La circunstancia 11 de agravación del homicidio fue adicionada al artículo 104 de la Ley 599 de 2000 a través del artículo 26 de la Ley 1257 del 4 de diciembre de 2008, por la cual el Congreso de la República dictó "normas de sensibilización, prevención y sanción de formas de violencia y discriminación contra las mujeres" y reformó los Códigos Penal, de Procedimiento Penal y la Ley 294 de 1996 (por su intermedio se desarrolló el artículo 42 de la Constitución Política y se dictaron normas " para prevenir, remediar y sancionar la violencia intrafamiliar").

En la exposición de motivos que acompañó la presentación del proyecto de la ley 1257, en lo fundamental, se esgrimieron como razones de la iniciativa las siguientes:

a. La violencia contra las mujeres es una expresión de discriminación y constituye una violación de sus derechos humanos. 
b. Gracias al trabajo desplegado por organizaciones de mujeres de todo el mundo y a su lucha política, se logró el reconocimiento de que la violencia en su contra "no era producto del azar o un hecho de la esfera privada, sino que estaba intimamente vinculada con relaciones desiguales de poder entre varones y mujeres".

c. Las mujeres han exigido de los Estados medidas para sancionar, prevenir y erradicar la violencia en su contra; para reparar los efectos de la misma en sus vidas y para "develar" cómo la perpetuación de esa violencia "es una forma de mantener relaciones estructurales de subordinación".

d. Organizaciones de derechos humanos y los Sistemas Naciones Unidas e Interamericano de Derechos Humanos, han unido sus esfuerzos a la causa, para realizar acciones y trazar directrices que permitan la eliminación de todas las formas de violencia contra las mujeres. Ello condujo a la articulación de normas, estándares, programas y políticas internacionales, que al asumir la violencia contra las mujeres como problema de derechos humanos, les trasladan a los Estados las obligaciones de prevenir, erradicar y castigar esos hechos.

e. La violencia contra las mujeres, por su condición de ser mujeres, constituye uno de los obstáculos "para el logro de la igualdad entre varones y mujeres y para el pleno ejercicio de la ciudadanía".

f. Interpretar la violencia contra las mujeres en el marco de los derechos humanos, "obliga a que en los ámbitos público y privado se fortalezcan e incrementen las acciones y politicas dirigidas a prevenir, sancionar y eliminar la violencia contra ellas, en especial en los sectores de la justicia, la educación y la salud".

g. La violencia contra las mujeres, "como manifestación de las relaciones de poder desigual construidas históricamente entre hombres y mujeres, establecidas y aceptadas por la sociedad", debe abordarse "con una visión integral que comprometa los procesos de sensibilización, información y educación de toda la sociedad, con la finalidad de erradicar este terrible flagelo que agobia a la humanidad, impide la conformación de sociedades auténticamente democráticas, obstaculiza el acceso al desarrollo y afecta profundamente la salud mental de la sociedad".

h. Esa violencia, "basada en las relaciones de subordinación", la viven las mujeres en los ámbitos público y privado. Ocurre en el lugar de trabajo, en los centros de salud y educativos, en la relaciones intrafamiliares y de pareja, y en los espacios de la comunidad en general. "Por ello el Estado y la sociedad están obligados a prevenir, atender, investigar, sancionar y erradicar este fenómeno, y a proteger a las victimas ante situaciones de amenaza, vulnerabilidad o riesgo para su autonomía, su integridad, sus propiedades, su núcleo familiar y su participación en la vida política, económica y social del país, mediante el establecimiento de condiciones sustanciales y procesales para el disfrute real de sus derechos". 
i. Entre los instrumentos internacionales ratificados por Colombia, en virtud de los cuales se ha comprometido el país a adecuar su legislación interna y a adoptar las medidas necesarias para el cumplimiento cabal de los compromisos en ellos establecidos, relacionaron los proponentes-como fundamento del proyecto de ley_ la Convención para la Eliminación de todas las formas de Discriminación contra la Mujer (Asamblea General de las Naciones Unidas, 1979), la declaración y plataforma de acción de Beijing de 1995 (calificado como el plan más progresista que jamás había existido para promover los derechos de la mujer), la Convención Interamericana para Prevenir, Sancionar y Erradicar la Violencia contra la Mujer (Convención de Belém do Pará, aprobada en 1994 y sancionada en 1996) y los Protocolos para Prevenir, Reprimir y Sancionar la trata de Personas, especialmente Mujeres y Niños, que complementa la Convención de las Naciones Unidas contra la Delincuencia Organizada Transnacional (adoptado en 2000, en Palermo, Italia) y el Facultativo de la Convención sobre la Eliminación de todas la formas de Discriminación contra la Mujer (1999).

j. Como fundamento constitucional de la propuesta, de otra parte, se mencionaron, entre otros, los artículos 13 ("todas las personas nacen libres e iguales ante la ley" y gozarán de las mismas oportunidades "sin ninguna discriminación por razones de sexo"), 42 ("las relaciones familiares se basan en igualdad de derechos y deberes de la pareja y en el respeto recíproco entre todos sus integrantes") y 43 de la Carta Política ("la mujer no podrá ser sometida a ninguna clase de discriminación").

k. Señalaron las Senadoras y Senadores que presentaron la iniciativa, por último, su anhelo de contribuir con esa ley "a eliminar el silencio social y la falta de acciones concretas para prevenir, sancionar y erradicar la violencia contra las mujeres por su condición de mujeres, dada la gravedad de sus consecuencias sociales, económicas y, especialmente, sobre su vida y su salud". Anunciaron dentro del contenido del proyecto algunas modificaciones al Código Penal. Particularmente la consagración del acoso sexual como delito y de "agravantes específicos en el caso de conductas violentas dirigidas contra las mujeres por el hecho de ser mujeres".

3. Una de esas agravantes, asociada al homicidio, como ya se dijo, fue la de causar la muerte a una mujer "por el hecho de ser mujer". E inscrita la misma en una ley dirigida a prevenir y a erradicar la violencia contra las mujeres que se origina principalmente en las relaciones de desigualdad históricas con los hombres, no puede tener el alcance que le dio el Tribunal Superior de Medellín, que la hizo corresponder al feminicidio o asesinato de mujeres por razones de género, un delito que a su juicio se encuentra motivado por la misoginia, es decir, por el desprecio y odio hacia ellas.

Matar a una mujer porque quien lo hace siente aversión hacia las mujeres, no se duda, es el evento más obvio de un "homicidio de mujer por razones de género", que fue la expresión con la cual se refirió al feminicidio 
la Corte Interamericana de Derechos Humanos en la sentencia del 16 de noviembre de 2009, expedida en el caso GONZÁLEZ Y OTRAS ("CAMPO ALGODONERO") VS. MÉXICO. Pero también ocurre la misma conducta cuando la muerte de la mujer es consecuencia de la violencia en su contra que sucede en un contexto de dominación (público o privado) y donde la causa está asociada a la instrumentalización de que es objeto.

En otros términos, se causa la muerte a una mujer por el hecho de ser mujer, cuando el acto violento que la produce está determinado por la subordinación y discriminación de que es víctima, de lo cual resulta una situación de extrema vulnerabilidad. Este entorno de la violencia feminicida, que es expresión de una larga tradición de predominio del hombre sobre la mujer, es el que básicamente ha servido de apoyo al legislador para considerar más grave ese tipo de violencia que se genera en un contexto de desigualdad y que se busca contrarrestar legítimamente con la medida de carácter penal examinada e igual con las demás de otra naturaleza adoptadas en la Ley 1257 de 2008.

Significa lo precedente que no todo asesinato de una mujer es feminicidio y configura la causal 11 de agravación del artículo 104 del Código Penal. Se requiere, para constituir esa conducta, que la violencia que la cause esté asociada a la discriminación y dominación de que ella es objeto.

Particularmente, en contextos de parejas heterosexuales -que conviven o se encuentran separadas-, el maltrato del hombre para mantener bajo su control y "suya" a la mujer, el acoso constante a que la somete para conseguirlo, la intimidación que con ello le produce, el aumento en la intensidad de su asedio y agresividad en cuanto ella más se aproxima a dejar de "pertenecerle" y la muerte que al final le causa "para que no sea de nadie más", claramente es el homicidio de una mujer por el hecho de ser mujer o "por razones de género".

Ese elemento adicional que debe concurrir en la conducta para la configuración de la agravante punitiva del feminicidio, es decir, la discriminación y dominación de la mujer implícita en la violencia que provoca su muerte, obviamente debe probarse en el proceso penal para que pueda reprocharse al autor. En consecuencia, en ningún caso cabe deducirla de la simple circunstancia de ser el autor del delito un hombre y la víctima una mujer, sino que ha de fundarse en evidencias demostrativas de la situación de abuso de poder en que se encontraba la última.

4. En el caso sometido a consideración de la Sala se estableció que el procesado era el esposo de la víctima y tenían una hija de seis años de edad. Tres años antes de que él decidiera matarla, le propinó nueve puñaladas. Lo hizo, según su cuñada FAV, porque le dio "un ataque de celos". Volvió a la casa días después, aún convaleciente la víctima, y se quedó allí contra la voluntad de ésta. La amenazaba con llevarse a la hija común si lo obligaba a irse. 
Ese escenario ya es el de una mujer maltratada por un hombre que no se relaciona con ella en un plano de igualdad sino que la subordina, como infortunadamente aún le sucede a muchas en nuestra sociedad, todavía atada en buena parte al machismo ancestral que propició la existencia en el Código Penal de 1890 de una norma que consideraba "inculpable absolutamente" la conducta del hombre consistente en

"cometer el homicidio en la persona de su mujer legítima, o de una descendiente del homicida, que viva a su lado honradamente, a quien se sorprenda en acto carnal con un hombre que no sea su marido; o el que cometa con la persona del hombre que encuentre yaciendo con una de las referidas; y lo mismo se hará en el caso de que los sorprenda, no en acto carnal, pero sí en otro deshonesto, aproximado o preparatorio de aquel, de modo que no pueda dudar del trato ilícito que entre ellos existe" (Art. 591-9).

Un mandato contrario, de "inculpabilidad absoluta" de la mujer que descubriera a su marido en acto carnal o preparatorio del mismo con una mujer, desde luego no existía.

El procesado AOR, más allá de los celos, que en casos como el presente son la expresión del macho dominante que no reconoce la libertad de su pareja para dejarlo, claramente nunca vivió una situación como la descrita en la norma transcrita, que con seguridad obligaría otras consideraciones. Simplemente, "por sospecha de que la persona amada mude su cariño" (que es como el diccionario de la Real Academia Española define "celoso" o "celosa"), resolvió perseguir a SPC y acuchillarla nueve veces.

La segunda parte de la historia confirma el contexto de dominación en el que finalmente ocurrió el homicidio el 17 de noviembre de 2012. La mujer, en contra de lo que quería, tuvo que seguir soportando al hombre a su lado, en la misma casa, temerosa de que si lo obligaba a marcharse se llevara con él a su hija. Se deduce lo anterior de la entrevista que rindió la hermana de la víctima. Esta afirmó, en efecto, que constantemente "S lo echaba de la casa y él no se iba". Y sólo accedió a hacerlo después de que un día, dos meses antes de los hechos, por encontrarla chateando "en Facebook", le propinó varios puñetazos. El hombre se fue a vivir cerca.

La cadena de violencia, al irse AOR, no se detuvo. Aumentó si se tiene en cuenta el acoso constante a que sometió a la mujer durante esos dos meses. "A todas las horas" -recordó FAV- la llamaba a sus teléfonos fijo y celular "para comprobar que ella estaba sola" y los viernes, por lo general, iba embriagado hasta el frente de su casa y le lanzaba amenazas. Por "sobre su cadáver" se conseguiría otro, le había dicho al marcharse de su lado. "Perra sucia te voy a matar", le gritó algunas veces en sus borracheras. Unos quince días antes del homicidio, según la declaración de la señora FAV ante la Policía Judicial, "...A se emborrachó mucho y subió y le gritó que le regalara la niña a la tía, o sea a mí, o que se la entregara a Bienestar Familiar que en cualquier momento a ella le iba a pasar algo...". 
Agregó la entrevistada que en la semana que siguió “...ella le dijo que se fuera de por ahi que no quería volverlo a ver, que se fuera y que hiciera una vida y A le dijo que sí que él se pensaba ir, y le dijo a la niña (la hija) que se iba a ir y que era para lejos, que porque la mamá lo quería hacer matar y ya no lo quería y se quería conseguir a otro".

Lo que sucedió el viernes anterior al crimen y el sábado cuando ocurrió, lo contó la declarante en los siguientes términos:

“...este viernes que pasó $S$ se fue por urgencias para donde quedaba el seguro social porque tenía un pie hinchado de un tatuaje que se hizo, y A llamó y la niña contestó y le dijo que la mamá estaba donde el médico y A le dijo que no que ella estaba con el mozo, a las diez de la noche ella le contestó el teléfono de la casa y ella le dijo marica deje de chimbiarme, que yo no tengo ningún mozo, vos no ves que ni siquiera salgo de la hijueputa casa le tiró el teléfono y le apagó el celular, el sábado la llamó a las 9 de la mañana le dijo que le pasara a la niña que tenía que hablar con ella, y A le dijo a la niña que él la quería mucho y que todo lo que pasaba era por amor, y que le dijera a la tía o sea a mí y a la hermanita que la cuidaran mucho, a las once de la mañana A volvió a llamar y $S$ le dio el afán que tenía que salir que tenía que salir, se bañó y se colocó una blusa unas chanchas y me dijo a mí: F no me demoro, yo bajo hasta el cuadradero y me devuelvo ahi mismo, esté tranquila...".

Fue la última vez que FAV habló con su hermana. La volvió a ver, muerta, en el Instituto de Medicina Legal, a donde se dirigió luego de enterarse por las noticias de su fallecimiento.

"A fue el que la mató", "yo estoy segura que fue él", le dijo la entrevistada a la Policía Judicial sin saber todavía de los sucesos ocurridos en la tarde del 17 de noviembre de 2012 en el motel Romantic Suites de Medellín.

Se demostró con la versión anterior, no hay duda, que el procesado, como si se tratara de una cosa, sentía de su propiedad a SPC. Era evidente que la negaba como ser digno y con libertad. La discriminaba. La mantenía sometida a través de la violencia constante. Después de apuñalarla tuvo el descaro de instalarse nuevamente en su casa, contra la voluntad de ella, cuando aún se recuperaba de las heridas físicas que le había causado. Nunca dejó de acosarla. Nunca de intimidarla. Ella no dejó de pedirle que se fuera. Y cuando al fin se marchó, luego de una nueva agresión física, la continuó hostigando, le siguió haciendo saber que era él o ninguno y que la mataría.

Todo eso, claramente para la Corte, no es una historia de amor sino de sometimiento de una mujer por un hombre que la considera subordinada y se resiste al acto civilizado de entender que la debe dejar en paz porque ella ya no lo quiere, y elige ejecutar el acto más contundente de despotismo que es la eliminación de la víctima de la relación de poder. 
Es manifiesto, entonces, que el procesado cometió el homicidio contra SPC "por el hecho de ser mujer" y en esa medida se equivocó la segunda instancia al suprimir esa circunstancia del atentado contra la vida, la cual hizo parte del cargo libremente aceptado por AOR. Por ende, se casará parcialmente el fallo impugnado para declarar que en la conducta concurrió la agravante 11 del artículo 104 del Código Penal.

Esa decisión no tiene impacto en la pena impuesta. Simplemente porque el juzgador, equivocadamente, no se movió del extremo mínimo del primer cuarto en el que dosificó la pena, a pesar de concurrir dos agravantes específicas del homicidio. Bastaba una de estas, eso es lógico, para tipificar la conducta como homicidio agravado. La otra, necesariamente, debía significar un incremento punitivo. Pero como le pareció igual de grave al juzgador una agravante que dos y los sujetos procesales con interés en el punto no impugnaron la determinación, no está dentro de las facultades de la Corte remediar la situación.

5. En relación con la rebaja punitiva derivada del allanamiento a cargos, que el Tribunal estableció en el $50 \%$ de la pena imponible -la mayor permitida por el artículo 351 de la Ley 906 de 2004-, el censor no presentó ninguna censura susceptible de examen en casación. Y la objeción que al respecto realizó la Procuradora Delegada en su intervención ante la Corte, fundada en su consideración de que la conducta imputada, en virtud del feminicidio, merecía sólo el descuento del $30 \%$ decretado por el a quo, no enmarca la comprobación de un error probatorio o jurídico del ad quem, o la transgresión de un derecho fundamental, que le sea dable corregir a la Sala.

La segunda instancia estimó que la conducta procesal del sindicado ameritaba la mencionada reducción en el castigo, ella no vulnera la legalidad y las consideraciones en que apoyó la decisión -aunque no se compartancorresponden a un criterio jurídico razonable, imposible de controvertir en desarrollo del recurso extraordinario de casación. Así, pues, no se puede acoger el punto de vista de la Delegada.

En virtud de lo expuesto, la Sala de Casación Penal de la Corte Suprema de Justicia, administrando justicia en nombre de la República y por autoridad de la Ley (...)

\section{Comentario}

La violencia de género ejercida contra la mujer es un fenómeno tan detestable como preocupante, que se presenta -con mayor o menor frecuencia- alrededor del globo y del que, naturalmente, Colombia no escapa. La gravedad de la situación y la mayor conciencia que hay sobre la necesidad de erradicar esta forma de violencia, explica que en los últimos años las autoridades nacionales hubieran tomado diversas medidas, muchas de ellas penales, con las que se pretende acompasar la legislación colombiana con las de los demás países del entorno, al igual que con las 
exigencias previstas en diversos estatutos internacionales -incluso, los no vinculantes o de soft law-. Al ánimo indicado obedecen las leyes 294 de 1996, 1257 de 2008 y, de modo más reciente, la 1761 de 2015, mediante las cuales se introdujeron modificaciones al ordenamiento penal, tratándose de la violencia de género y, en particular, de aquella ejercida contra la mujer.

Esta relativa inestabilidad legislativa, que obliga tener presente las normas sobre la materia de los años 1996, 2000 (Código Penal), 2008 y 2015, provoca, huelga decirlo, un efecto negativo sobre la seguridad jurídica y, de hecho, la primera advertencia que debe hacerse es la relativa a que la sentencia objeto de comentario -la única que, al momento de este comentario, ha producido la Corte Suprema de Justicia sobre el tema- se ocupa del numeral 11 del artículo $104 \mathrm{CP}$, introducido por la Ley 1257 y que, actualmente, se encuentra derogado tras la reciente entrada en vigor de la Ley 1761 de 2015.

Al hilo de lo anterior, no debe dejar de mencionarse que la decisión comentada fue justificada por la Sala en una necesidad fundamentalmente propedéutica (la de ilustrar sobre el supuesto de feminicidio incluido por la Ley 1257 que, se reitera, ya fue derogado), tras reconocer que el sentido de su decisión no afectaba la tasación de la pena, es decir, que no tendría incidencia práctica y concreta frente al caso sub iudice.

Bien, de acuerdo con la Resolución 48/104 de la Organización de las Naciones Unidas de 1994, existe violencia contra la mujer cuando, en razón del sexo de la víctima, el victimario le inflige daños o sufrimientos físicos, sexuales o sicológicos; este punto de partida es el resultado de la evolución jurídica del tratamiento de la violencia contra la mujer, desarrollado en la Declaración sobre la Eliminación de la Discriminación contra la Mujer (1967), la Convención sobre la Eliminación de Todas las Formas de Discriminación contra la Mujer (1979), la Declaración sobre la Eliminación de Violencia contra la Mujer (1993) y en otra serie de convenciones, recomendaciones, y protocolos, cada vez más sofisticados y numerosos, en los cuales se insistía en la tipificación generalizada de los delitos de violencia de género, teniendo como referente el comportamiento descrito por la ONU, mencionado al inicio de este párrafo.

La legislación colombiana fue una de las primeras en incorporar las exigencias de los mencionados instrumentos: ya en el año de 1996 se promulgó la Ley 294 que estaba referida, de modo genérico, a la violencia intrafamiliar y, aunque esta forma de violencia afecta en mayor medida a la mujer, al menos en términos estadísticos, lo cierto es que dicha normatividad no aludía en forma directa al fenómeno de la violencia contra la mujer.

En tal sentido, la Ley 1257 de 2008 resultó mucho más expresa y severa, conforme lo sugiere su propio título: "por la cual se dictan 
normas de sensibilización, prevención y sanción de formas de violencia y discriminación contra las mujeres, se reforman los Códigos Penal, de Procedimiento Penal, la Ley 294 de 1996 y se dictan otras disposiciones". Esta legislación, tal y como lo reconoce su exposición motiva, responde a las exigencias hechas por algunos grupos de activistas al Estado para que tomara medidas drásticas frente a la violencia contra las mujeres $\mathrm{y}$, con ella, se quería extraer del ámbito privado una serie de comportamientos que, vistos de manera panorámica, hacían parte de una estructura social machista; así, la violencia de género pasó a ser un asunto público y un problema al que el Estado debía poner freno. Consecuente con este punto de partida, la Ley 1257 introdujo -por primera vez- en la legislación criminal colombiana la figura del feminicidio, si bien como un delito innominado, al amparo del complemento que hacía el numeral 11 del art. 104 al art. 103, bajo la siguiente fórmula: "[e]l que matare a otro..." “... si se cometiere contra una mujer por el hecho de ser mujer".

Esta redacción describía el feminicidio de modo sencillo y abarcaba -por su generalidad- diversas situaciones en las cuales una mujer era muerta en el marco de la violencia de género, al prescindir de enumeraciones casuísticas que limitaran su aplicación. Sin embargo, su definición estaba ligada a un ingrediente subjetivo, necesarísimo en orden a diferenciar el feminicidio de los supuestos de homicidio simple en los cuales el sujeto pasivo fuera una 'mujer', pero cuya inclusión oponía, al mismo tiempo, dificultades significativas a la subsunción en cada caso. Este punto es, por cierto, el que mayor interés suscita en la sentencia examinada.

En el caso juzgado, el debate en torno a la aplicación o no de la agravante prevista en el número 11 del art. 104 del Código Penal deriva de la discusión sostenida en las instancias, pues, en la primera, el agente fue condenado por un homicidio doblemente agravado por los numerales 1. y 11. del art. 104 ibídem, mientras que, tras la apelación, a ojos del ad quem, la condena sólo podía agravarse en razón del nexo familiar entre la víctima y el victimario, descartando la agravación por feminicidio. Ante este panorama, el apoderado de las víctimas interpuso recurso de casación para que la Corte determinara si los hechos sometidos a juicio constituían un uxoricidio $\mathrm{y} / \mathrm{o}$ un feminicidio.

La Corporación encontró que la calificación jurídica correcta de la conducta era la de feminicidio (numeral 11.) y que, por lo tanto, se le debía dar aplicación, no sólo al agravante del numeral 1. del art. 104, sino, también, al previsto en el numeral 11. del mismo artículo. Lo anterior, en la medida en que, para la Corte, una conducta feminicida no exige necesariamente- el concurso de un sentimiento misógino y, por lo tanto, no es preciso comprobar un odio irracional y generalizado hacia todas las mujeres; por el contrario, en tratándose del ámbito relacional, indica la Sala, cuando una relación sentimental se caracteriza por reiterados actos 
de dominación, en que se trata a la mujer como un ser desprovisto de libertad y se la reduce a un objeto de dominio y de posesión por parte de su pareja, dicha cosificación es la prueba fehaciente -y suficiente- de los actos de discriminación que, para la Corte, permiten afirmar la existencia de un hecho de violencia de género.

De esta forma, se explica en la sentencia, quienes ejercen actos de violencia de género contra la mujer dentro del ámbito relacional, lo hacen, a veces, sin ser conscientes de que su proceder hace parte de un sistema de dominación sobre las decisiones vitales de las mujeres, pues su obrar ha sido predeterminado por una nociva cultura machista. De ahí que, aunque el autor de dichos actos no profese de manera positiva un sentimiento de desprecio hacia toda la comunidad femenina, sus acciones perpetúan aunque él no lo sepa- un odioso ciclo de violencia contra la mujer.

Una situación de absoluto control, dominación y posesión sobre la víctima es, ciertamente, una muestra de desprecio por la libertad de la otra persona, al igual que una negación de su dignidad como ser humano, el cual, atendidas las palabras de I. Kant dentro de su "Fundamentación de la Metafísica de las Costumbres", ha de considerarse un fin en sí mismo; por lo tanto, cosificar a una persona, reducirla a un objeto de propiedad que es incapaz de tomar decisiones sobre su destino, es un acto vejatorio y denigrante. En este sentido, la insistencia de la Corte en las reiteradas señales de dominio que se desprenden de la exposición de los hechos resulta apenas natural, en orden a afirmar el feminicidio en el caso concreto: las agresiones previas a la muerte de la víctima, las constantes amenazas que sufrió, la instigación y persecución padecidas por ella, constituyen muestras de su cosificación.

Sin duda, un trato denigrante y la negación sistemática de las esferas más íntimas de la libertad de una persona constituyen un acto de violencia. No obstante, resulta apresurado aseverar que la negación de la dignidad de la pareja sentimental es un acto exclusivo de la violencia de género contra la mujer, pues el trato desconsiderado, posesivo y denigrante puede presentarse en el marco de cualquier relación sentimental, sin importar que la misma sea una pareja homosexual, heterosexual o, incluso, una relación poliamorosa, es decir, un vínculo sentimental entre más de dos personas que constituyen nexos relacionales con el mismo ánimo de estabilidad que una pareja convencional; además, quien da tales tratos puede ser cualquiera de las partes de la relación, hombre o mujer.

En este sentido, conviene aclarar que la figura del feminicidio se traduce, conforme se indicó antes, en la muerte de una mujer por el hecho de ser mujer y no se afinca en la circunstancia de ser la pareja del agresor, aunque ambos extremos puedan coincidir en ciertos casos. Por ello, acorde con esta definición, la figura examinada precisa que exista efectivamente una actitud machista frente a toda la población femenina, de tal manera que hay 
feminicidio cuando se le da muerte a la mujer que es pareja actual o pasada del agresor, por el hecho de ser mujer (feminicidio íntimo) y, también, cuando se da muerte a una mujer desconocida o con la que no se tiene relación sentimental -pasada o presente-, por el hecho de ser mujer (feminicidio público). Las dos hipótesis tienen en común la aversión irracional del agresor hacia la mujer, trátese de su pareja -anterior o actual-o no.

En el orden de ideas planteado por la Corte, en una relación posesiva marcada por la celotipia, necesariamente subyace una discriminación en razón de la identidad sexual, el género o la inclinación sexual de la pareja, postura esta que, además de reduccionista, si se aplicara con el mismo rasero a todos los homicidios circunstanciados por una relación de pareja, implicaría una violencia de género constante que no solo puede ser ejercida por los hombres contra las mujeres, sino, también, por las mujeres contra los hombres e, incluso, entre personas de un mismo género e inclinación sexual. Los celos y la idea de posesión sobre el otro asociada a los mismos no son, pues, privativos de los hombres.

Ahora bien, si se tiene en cuenta el art. 13 de la Constitución (1991), cuyo texto estatuye la igualdad, no solo material sino también formal, de todas las personas frente a la ley, resulta sospechosa -siempre en clave constitucional- la aplicación diferenciada de dos tipos penales, homicidio y feminicidio, frente a dos hechos idénticos, en los que sólo cambia el sexo de quienes son sujetos activo y pasivo.

Si bien es cierto que la política criminal colombiana se ha encaminado a proteger de forma reforzada a las mujeres en los casos de violencia de género y que la legislación precitada obedece, precisamente, a esa orientación, no puede pasarse por alto que esa protección reforzada debe realizarse dentro del marco constitucional, respetando los principios de un derecho penal liberal y, desde luego, con base en los soportes fácticos y probatorios de cada caso; por eso, asumir que un delito pasional es, necesariamente y en todos los casos, sinónimo de violencia de género, sin que existan pruebas suficientes del sentimiento de desprecio hacia el género de la pareja que anima al agresor, es, cuando menos, vejatorio del principio de legalidad.

Con lo dicho no se pretende negar la ocurrencia de feminicidios íntimos circunstanciados por los celos del sujeto agente; tampoco se cuestiona el que una concreta actitud dominante y posesiva tenga origen en la discriminación del sexo femenino que hace el agresor; lo que se discute es que tal nexo pueda presumirse sin más, debido a que, teniendo como referente el derogado numeral 11. del art. $104 \mathrm{CP}$, al obrar de tal modo se invierten las cargas probatorias y se impone un especie de in dubio contra reo.

Tampoco tranquiliza que la Corte afirme que el feminicidio es la expresión más grave de una cultura machista y que, por lo tanto, el feminicida, probablemente no es consciente de su desprecio discriminatorio hacia las 
mujeres, señalando, al mismo tiempo, que en ello radica justamente la gravedad de su conducta. Pues, aunque es cierto que la cultura colombiana está muy permeada de comportamientos machistas, el que esta sea una conducta reiterada por algunas personas y que esté asentada en la cultura no puede ser, en realidad, un argumento para juzgar a alguien con un rasero más drástico: la responsabilidad penal es, no se olvide, de naturaleza individual y nadie puede ser juzgado ni condenado, mucho menos su comportamiento agravado, en razón del actuar de terceros que histórica o estadísticamente han procedido en el mismo sentido. El juicio de reproche en materia penal es de carácter singular y nunca colectivo.

Naturalmente, admitir que las personas no son conscientes de la incorrección de su proceder genera graves problemas en la aplicación de la ley penal, pues remite a los complejos problemas que suscita el error; además, respecto de delitos que incorporan un ingrediente subjetivo adicional al dolo -como el de feminicidio-, es aún mayor la exigencia para el fallador al momento de realizar el juicio de tipicidad, porque debe acreditar que el sujeto activo actuó con motivaciones especiales (fines, ánimos o móviles). En consecuencia, quien da muerte a una mujer, debe saber que le está dando muerte precisamente por su condición y ello ha de estar probado en el caso concreto, sin que sea posible presumirlo en perjuicio del reo.

Por lo apuntado, la decisión de la Corte suscita serios reparos en la medida en que se apartó del marco previsto por el numeral 11. del art. 104 $\mathrm{CP}$, al remplazar los elementos subjetivos del tipo penal por ingredientes que, si se mira bien, no estaban contemplados en el mismo. Esto, en tanto que no se pronunció sobre los móviles de discriminación hacia la mujer que tenía el autor y, en vez de ello, decidió reemplazarlos por los comportamientos celotípicos dominantes y posesivos del agresor contra su víctima; presumiendo que los mismos sugieren, indefectiblemente, un desprecio hacia la mujer, sin que, para el caso concreto, se haya determinado el rechazo o aversión del sujeto activo frente a las mujeres.

El problema radica, entonces, en que no toda la condición de celotipia implica un rechazo de género y, por supuesto, no toda la violencia de género parte de manifestaciones celotípicas; en tal virtud, la Corte debió fundamentarse en las evidencias dentro del caso concreto para tomar su decisión.

La interpretación de la Sala fuerza, quizás de forma excesiva, el principio de legalidad en su intento por sortear la -evidente- dificultad que representa para el juez, en clave probatoria, la constatación de los elementos subjetivos diferentes del dolo. Desde luego que, por su propia naturaleza, los ingredientes subjetivos resultan inasibles para el juzgador y, por ello, es normal -mejor, necesario- que tales elementos se objetiven, pero esos referentes objetivos que permiten inferirlos deben tener la fuerza suficiente para superar el estándar probatorio que se exige en materia 
penal; eso, precisamente, se extraña en la sentencia comentada, pues entre los argumentos no se deja ver un vínculo fuerte entre los comportamientos de dominación en el ámbito relacional y una aversión hacia la mujer, conforme lo exigía la disposición penal aplicada que utilizaba la fórmula "por el hecho de ser mujer".

Otra cosa es el análisis del delito de feminicidio de cara a la ya mencionada Ley 1761 de 2015 (Rosa Elvira Cely), a cuyo amparo, según ha dispuesto el legislador, sí puede prescindirse del concreto ingrediente subjetivo distinto del dolo aludido en precedencia; la diferencia estriba en que, en este último caso, tal posibilidad viene dada por el creador de la ley.

Como consecuencia de ello, es verdad, la labor del juez se simplifica en la medida en que puede reemplazar el ingrediente subjetivo tantas veces aludido por una serie -muy variada- de elementos objetivos alternativos; aunque esta opción, también es cierto, amplía el ámbito del actual tipo penal de feminicidio hasta abarcar situaciones ajenas a la violencia de género; así, por ejemplo, bajo la nueva regulación se dispone que constituye un feminicidio toda muerte de una mujer en que se pruebe que el victimario tiene o tuvo "una relación familiar, íntima o de convivencia con la víctima, de amistad, de compañerismo o trabajo y ser perpetrador de un ciclo de violencia física, sexual, psicológica o patrimonial que antecedió el crimen contra ella" (art. 104A a)), que cometió "el delito en aprovechamiento de las relaciones de poder ejercidas sobre la mujer, expresado en la jerarquización personal, económica, sexual, militar política o sociocultural" (art. 104A c)) o "[q]ue existan antecedentes o indicios de cualquier tipo de violencia o amenaza en el ámbito doméstico, familiar, laboral o escolar por parte del sujeto activo en contra de la víctima o de la violencia de género cometida por el autor contra la víctima, independientemente de que haya sido denunciado o no" (art. 104A e)).

Como queda ilustrado con los tres ejemplos transcritos, la nueva legislación casuística y pormenorizada, que emula las consagraciones típicas del feminicidio que se han usado en países como El Salvador, Guatemala, México y Nicaragua, permite un análisis como el expuesto en la sentencia comentada, pues el texto legal posibilita dicha interpretación; lo anterior, al margen de sus falencias en punto de la técnica legislativa empleada o de los excesos que evidencia la política criminal que la inspira, como ocurre cuando, siempre a la luz del nuevo delito, se puede condenar por feminicidio cuando existan indicios de amenazas no denunciadas (!).

Muy probablemente, la sentencia comentada se convertirá en un hito dentro de la jurisprudencia nacional y está llamada a servir de guía para los jueces en la aplicación del delito de feminicidio recientemente incorporado al plexo legal, respecto del cual resulta un precedente válido, sin perjuicio de los reproches que cabe hacerle, conforme viene de verse, frente a lo previsto en el número 11., ya derogado, del art. $104 \mathrm{CP}$. 


\section{Referencias}

Constitución Política (1991). Congreso de la República de Colombia. Colombia.

Ley 294 de 1996. Por medio de la cual se desarrolla el artículo 42 de la Constitución Política y se dictan normas para prevenir, remediar y sancionar la violencia intrafamiliar. Diario Oficial No. 42.836. Congreso de la República, julio de 1996.

Ley 599 de 2000. Por medio de la cual se expide el Código Penal. Diario Oficial No. 44.097 Congreso de la República, julio de 2000.

Ley 1257 de 2008. Por la cual se dictan normas de sensibilización, prevención y sanción de formas de violencia y discriminación contra las mujeres, se reforman los Códigos Penal, de Procedimiento Penal, la Ley 294 de 1996 y se dictan otras disposiciones. Diario Oficial No. 47.193. Congreso de la República, diciembre de 2008.

Ley 1761 de 2015. Por la cual se crea el tipo penal de feminicidio como delito autónomo y se dictan otras disposiciones. Diario Oficial No. 49.565. Congreso de la República, julio de 2015.

Organización de las Naciones Unidas-[ONU] (1994). Declaración sobre la eliminación de la violencia contra la mujer. Resolución 48/104 de 1994 Recuperada de http:/ / www.uji.es/bin/organs/ui/legisla/int/7-r48-104.pdf

Organización de las Naciones Unidas-[ONU] (1967). Declaración sobre la Eliminación de la Discriminación contra la Mujer.

Organización de las Naciones Unidas-[ONU] (1979). Convención sobre la Eliminación de Todas las Formas de Discriminación contra la Mujer.

Organización de las Naciones Unidas-[ONU] (1993). Declaración sobre la Eliminación de Violencia contra la Mujer. 